\title{
Sons of Anarchy. Estudio ideológico, narrativo y mitológico de la serie de televisión
}

Víctor Hernández-Santaolalla, Sergio Cobo-Durán (Coord.). Barcelona, Laertes, 2017. 308 páginas.

\section{Reseña por Almudena Mata Núñez \\ http://dx.doi.org/10.12795/AdMIRA.2017.02.08}

El apogeo de las ficciones televisivas ha caracterizado la creación audiovisual de los últimos años, en los que han proliferado multitud de series, emitidas tanto por las cadenas tradicionales de televisión como por canales temáticos y plataformas de vídeo bajo demanda que propician el consumo en distintos dispositivos electrónicos. En este contexto, en 2008 apareció en la cadena estadounidense FX Sons of Anarchy, una serie sobre un club de moteros creada por Kurt Sutter. La ficción, que emitió sus siete temporadas hasta el año 2014, presenta un conjunto poliédrico de significados a los que acercarse desde un amplio abanico de posibilidades. Es así como, desde una perspectiva heteróclita, Víctor Hernández Santaolalla y Sergio Cobo Durán, coordinadores del volumen Sons of Anarchy. Estudio ideológico, narrativo y mitológico de la serie de televisión, convierten la conocida serie en objeto de un profundo estudio. Se trata de un libro que, aún naciendo desde la academia, se proyecta hacia un público lector que es también espectador televisivo. De esta forma, el análisis abarca tanto elementos de la propia serie como el entorno en que se enmarca. Para ello, los autores dividen el texto en cinco bloques: un primero contextual, seguido del estudio ideológico en el segundo bloque, mitológico en el tercero y narrativo en el cuarto, para finalizar con un quinto apartado dedicado a los elementos sonoros.

Tras una breve introducción que sitúa ante el contenido del volumen, el libro comienza con un artículo de Valeriano Durán Manso, quien se dedica a explorar las conexiones de la serie con la representación masculina del cine hollywoodiense de los 50. El ansia de libertad y la oposición a las normas sociales son rasgos que los personajes de Sons of Anarchy comparten con los rebeldes del cine clásico que, sin duda, cambiaron la representación del héroe. La tendencia a la violencia en un ambiente hostil en el que los hombres deben aparentar dureza es una característica que se refleja en la serie, la cual vende al espectador un modelo de masculinidad que se debate entre el conflicto interno y la agresividad externa. Las motos y las chupas de cuero que identifican a la banda forman también parte de la estética de esos jóvenes inconformistas de gran atractivo físico y una profunda complejidad psicológica.

Esta narrativa masculinizada es, como señalan Irene Raya Bravo y Pedro Vasallo Alcedo en el segundo capítulo, una focalización de la producción hacia un público muy concreto por el que 
se distingue la cadena emisora. El contenido de violencia de la serie se ajusta a un conjunto de obras que identifican a FX por su contenido controvertido y la calidad de la ficción de temática compleja y tendiente a un modelo formal más cinematográfico. Otras propuestas de la cadena se ajustan igualmente a este patrón, estableciendo conexiones más que evidentes con Sons of Anarchy, como ocurre con Justified, con la que comparte rasgos del western tales como el mito de la frontera y la civilización que impone unas normas que constriñen la libertad del oeste, que se rige por sus propias reglas. Entre los vínculos con otras series destaca el que la serie de Kurt Sutter mantiene con otra del mismo creador: The Shield. Así lo explica Adrián González Viña en el cuarto capítulo del libro, en el que se ponen de relieve los guiños que desde la serie de moteros se hace a la ficción hermana.

Tras la contextualización inicial en el aspecto narrativo y de producción, Cristina Algaba y Elena Bellido Pérez destacan uno de los aspectos más significativos de Sons of Anarchy: su reescritura de la tragedia shakesperiana. La relación con Hamlet es la más evidente, pero las autoras indican otras influencias míticas del dramaturgo inglés, que se aprecian, siguiendo el estudio de A. C. Bradley, en el destino trágico del héroe, cuya muerte provoca grandes cambios políticos.

Es precisamente el trasfondo político el que se explora en el segundo bloque del libro. Antonio Pineda comienza con una aproximación a la ideología anarquista y cómo esta es representada en la serie, ya desde su propio título. No obstante, en Sons of Anarchy esta opción política no se plantea desde una visión positiva de la autorregulación entre iguales, sino que se expresa mediante la oposición las leyes del Estado y el anticapitalismo contra grandes cadenas comerciales. Es el llamado anarcocapitalismo el que analiza Samuel Fernández Pichel, resaltando las estrategias empresariales que mueven a SAMCRO en su negocio ilegal de venta de armas. La violencia es inherente al propio sistema económico capitalista que tan ligado se encuentra a la cultura norteamericana y que se expande de forma imparable a nivel mundial. Las relaciones de intercambios tienen en la serie especial importancia ya que remite, de nuevo, a al mito de la frontera, aportando significado narrativo a la trama.

De esta manera, la violencia en todas sus formas, la oposición al orden establecido y el ansia de libertad son elementos definitorios de una ficción en la que los personajes se alzan como figuras que velan por el cumplimiento de las normas que el propio grupo se ha otorgado, las cuales buscan la justicia y seguridad en un ambiente de inestabilidad y enfrentamiento. Se trata del concepto de vigilantismo, que Víctor Hernández Santaolalla disemina minuciosamente siguiendo las características de Johnston. La voluntad de la acción organizada, la autonomía de SAMCRO como grupo que ejerce la fuerza de forma violenta para mantener la paz son algunos de los rasgos que los definen como vigilantes. 
La violencia explícita constante es, además, uno de los elementos por los que destaca Sons of Anarchy. Más que un recurso estético, la actitud violenta se convierte en la serie en un fundamento narrativo que es normalizado en tanto que se presenta como la única vía de solucionar los conflictos. El papel de esta conducta lo estudia Sara González Fernández, quien distingue la agresividad como una de las señas de identidad del club de moteros pues, como la estética de su vestimenta, el comportamiento amenazante y cruel los diferencia como grupo. No obstante, SAMCRO no es el único colectivo que hace uso de la violencia, ya que el resto de bandas que aparecen en la serie se rigen por un modo de actuación similar. La oposición respecto a estas se realiza, principalmente, a través de la caracterización racial, puesto que cada una de las asociaciones representa a un grupo social concreto. Así, Francisco Javier López Rodríguez lleva a cabo una exposición que recoge las bandas moteras presentes en Sons of Anarchy y su identificación con grupos de blancos, afroamericanos, latinos, supremacistas y asiáticos, ajustados a los estereotipos raciales correspondientes.

Por otro lado, en el tercer bloque del volumen se estudia el alcance mitológico en la narrativa de la serie. María del Mar Rubio Hernández firma el texto que introduce en la simbología de la producción audiovisual. El relato fundacional por parte del diario de John Teller y la figura del salvador encarnada por su hijo Jax son, quizá, las representaciones de mayor carga simbólica, pues articulan todo el relato desde principio a fin. A ellas se suman los ritos casi litúrgicos de la hermandad que forman los hombres de SAMCRO, a los que unen múltiples referencias a la muerte a través, sobre todo, de la iconografía de la parca. Los mitologemas como unidades de significado mínimas también están revisados en la serie, como ocurre con la historia de Agripina y su hijo Nerón, que se traslada a la relación entre Gemma y Jax Teller, como bien explican Mán Ángeles Martínez García y Antonio Gómez Aguilar.

Pero Sons of Anarchy no solo recoge referencias clásicas, sino que su construcción narrativa se adapta a las tendencias actuales de la cultura de masas. La recurrencia a mecanismos que permiten empatizar con un protagonista que no triunfa y se debate en un conflicto interno se enmarca en una comunidad con rasgos propios, basada, según exponen Javier Barraycoa Martínez y Jorge Martínez Lucena, en el sentimiento de pertenencia.

El cuarto bloque del libro se centra, por su parte, en el análisis narrativo de los personajes. Inmaculada Gordillo y Virginia Guarinos son las encargadas de establecer la mirada de género en una serie que desplaza a las mujeres al segundo plano de la acción, a pesar de contar con personajes femeninos fuertes y que, siguiendo la tendencia de las mujeres fálicas, ofrecen cierta resistencia a la debilidad y emoción habitualmente asociadas a lo femenino. Las mujeres de SAMCRO pueden ser violentas y crueles al igual que los hombres, pero nunca tienen un peso 
equivalente en la acción. El estudio pormenorizado de los roles masculinos lo realiza Virginia Luzón, quien establece la función narrativa de los personajes respecto al protagonista.

Otros recursos narrativos explorados en el libro son los tatuajes, que actúan tanto de elementos temáticos, como simbólicos capaces de aportar significados. Sergio Cobo Durán explora la relación entre estas marcas de tinta permanentes y el relato de Sons of Anarchy. El tatuaje del logo de la banda como identificativo de sus miembros o los que adornan el cuerpo de Jax a la vez que cuentan la historia de su pasado y su presente son solo algunos de los ejemplos que se encuentran a lo largo de toda la narración.

La historia de Sons of Anarchy se extiende, además, por otros medios. La expansión por otros soportes y la participación activa de la audiencia son aspectos claves para generar comunidad alrededor del producto audiovisual que no solo se ha vendido como serie, ya que también cuenta con cómics, libros, juegos para móvil y juegos de mesa en torno al mismo universo, creando, así, una propuesta transmedia basada en el simple trasvase de personajes de un medio a otro, según explican David Varona, Javier Lozano Delmar y Juan F. Plaza.

Después de tales exhaustivos análisis, el libro se cierra con un último bloque dedicado al estudio del elemento sonoro en la serie. Noor Yasmina Benchichah López realiza un primer acercamiento a la presencia de la música en la secuencia de inicio de Sons of Anarchy, la cual, además de contener los créditos iniciales, funciona a modo de resumen del contenido narrativo. Ya en las imágenes de la cabecera aparecen los símbolos que estarán presente a lo largo de los episodios, pasando por la familia, la violencia o la muerte, que también son nombrados en This Life, la canción que complementa esta introducción.

Un estudio más detallado del elemento sonoro en la serie es el que lleva a cabo Joaquín Marín Montín. En la banda sonora de Sons of Anarchy se incluyen las voces que aportan matices a los personajes, los usos idiomáticos que identifican los grupos de pertenencia, el componente musical de amplia carga simbólica e incluso ruidos ambientales que aportan realismo y verosimilitud a la imagen.

La música es por sí misma un aspecto a destacar, tal y como señala Jorge David Fernández Gómez. La alta presencia cuantitativa de canciones en la serie resalta su vinculación con la narración, pues las letras actúan como marcas musicales de lugares, situaciones o personajes. La adecuación del género musical a las escenas está cuidadosamente pensada, ya que se pretende producir una identificación en el tono de registro musical y dramático. De esta forma, a través del montage musical, las canciones refuerzan el significado de la trama a la vez que realizan un recorrido por la música popular estadounidense. 
Sin lugar a dudas, Sons of Anarchy. Estudio ideológico, narrativo y mitológico de la serie de televisión consigue articular todo un conjunto de estudios multidisciplinares que permite profundizar en una serie que va más allá del simple consumo televisivo. La violencia, la estética motera, el destino trágico de la venganza o el sentimiento de pertenencia a un grupo que se opone al orden establecido son tan solo algunos de los componentes de una producción audiovisual que ha causado sensación entre legiones de fans por todo el mundo y que, gracias a este volumen, ahora pueden comprenderse desde una óptica más completa. 